\section{Negotiation of Meaning and Language Acquisition by Indonesia EFL Learners}

\section{Hery Yufrizal}

Universitas Lampung, Bandar Lampung

\begin{abstract}
This study was aimed at investigating negotiation of meaning among Indonesian learners of EFL in English interaction. It was also intended to examine which type of tasks stimulate the learners to negotiate meaning. Forty undergraduate students were involved in this study. Information gap, Jigsaw, and Role-play tasks were given to students for dyadic interactions. The results show that the information gap tasks were more productive than the other two types of tasks. The study also shows that more interaction and negotiation of meaning were produced by the learners in the same gender and the same proficiency dyads when they were assigned the information gap and jigsaw tasks.
\end{abstract}

Keywords: negotiation of meaning, language acquisition, EFL learners.

This study addresses two important issues in relation to the effect of interaction and negotiation of meaning on second/foreign language acquisition. The first issue is concerned with the difference between the patterns of interaction and negotiation of meaning in second language settings and in foreign language settings. Interactions in a foreign language setting such as interactions among EFL learners in Indonesia, Thailand, Vietnam, and some Latin American countries, occur mostly in relation to language classroom learning. Interactions in the target language occur only in relation to classroom practice not for the sake of a purely communicative purpose. Many facts need to be explored from how these EFL learners acquire the language through interaction in the target language. For instance, questions such as when these learners are given communicative tasks in the target language will they use the language during the accomplishment of the tasks or will they switch to their L1 whenever communication breakdown occurs or potential to occur? Will they provide each with modifications of input, how and in what condition will they provide modification of input?

Will they produce modifications of output during the communication? If yes, will the modification of output be in the target like form? How far the communication features produced by these learners resemble or differ from the communication features in second language setting. These questions are necessary to add to our understanding of the foreign language acquisition as an important consideration for the development of studies in second language acquisition through interactions both in second and foreign language settings.

The second issue is related to situation in which negotiation of meaning, modification of input and modification of can be facilitated. Previous studies have shown that tasks play a very important role in determining the rate of second language learners' involvement in interaction and negotiation of meaning (see Pica et al, 1993 for detailed discussion). Pica et al(1993) propose that tasks that stimulate negotiation of meaning can be categorized into information gap tasks, jigsaw tasks, decision making task, problem solving task, and opinion exchange task. Courtney (1996) and Martyn (forthcoming) tried to see the effects of the task on second language learners' interaction and found that each task generate different amount of negotiation of meaning. However, other studies such as Plough and Gass (1993) and Foster (1998) found that besides that interaction arrangements play an important role in determining the negotiation of meaning. Plough and Gass found that dyadic arrangements play a very important role in making second language learners to be more involved in interactions.

This study attempts to answer three research questions:

a) Will Indonesian EFL learner negotiate meaning when they are given to opportunity to interact in English with other Indonesian EFL learners?

b) Which task type will stimulate the learners to negotiate meaning?

c) Under what dyadic arrangements will the learners negotiate more

\section{REVIEW OF UTTERATURE}

How the native speakers get across their message and how the nonnative speakers comprehend the message has been a major concern in the study of interactions for the last three decades. Long $(1981,1982)$ 
points out that non-native speakers benefit from interacting with native speakers by the justification of the native speakers' speech whenever the non native speakers show an indication of misunderstanding. On the other hand, the native speakers can check their interlocutors' understanding by extending comprehension check, request for clarification and request for confirmation. If the native speakers find that their interlocutors show misunderstanding, they can justify their rate of speaking, justify their message or simplify their speech. The speech modifications made the native speakers are believed to be an important aspect that helps the nonnative speakers comprehend and thus acquire the target language. Gassand Varonis (1985a and b), Pica and Doughty $(1985,1986)$ contend that non native speakers benefit not only from the speech modifications and justifications by the native speakers but they also benefit from the opportunity to negotiate meaning whenever communication breakdown occurs or potentially to occur. Long $(1981,1982)$, Gass and Varonis (1985a and b), Pica and Doughty $(1985,1986)$ and later on Swain (1985, 1996) have developed fundamental ideas for the studies of interactions in second/foreign language learning within the last three decades (see, Pica et al, 1989; Pica et al, 1991; Pica et al, 1996; Plough and Gass, 1993, Gass and Polio, 1996; Futaba, 1995, Holliday, 1995, Kasanga, 1996; Oliver, 1997, 2000, Shehadeh, 1999).

Most of negotiation of meaning studies both for the sake of comprehensible input and comprehensible output gain data from the interaction between native speakers (NSs) and non native speakers (NNSs) (Pica and Doughty, 1985; Varonis and Gass; Yule and MacDonald (1991, 1992; Pica et al 1989; Pica et al 1996). Some studies gained the data from interactions among non native speakers either from the same L1 background or different L1 background but mostly occurred in a second language setting or at least involving the researcher as the native speaker (Gass and Varonis, 1985, 1986; Futaba, 1996; Shehadeh, 1999; Martyn, forthcoming, Oliver, 1998, 2000). Only a few studies report the process of interaction and negotiation of meaning among foreign language learners in a foreign language setting. Kasanga (1996) for instance, studied the interaction among Zairian EFL learners in Zaire and reported that the EFL learners indeed negotiate meaning when they interact each other in English.

\section{Negotiation of meaning}

Negotiation of meaning is defined as a series of activities conducted by addressor and addressee to make themselves understand and be understood by their interlocutors. In this case, when native speaker (NS) and non native speakers (NNSs) are involved in an interaction, both interactants work together to solve any misunderstanding or non understanding that occurs or potential to occur checking each others' comprehension check, requesting for clarification and confirmation and by repairing and adjustments (Pica, 1988).

Pica, 1989 suggest that negotiation of meaning basically consisted of four interrelated moves. The moves are trigger, signal, response, and follow-up moves. Definitions and examples of each moves were completely described in Pica et al (1989) and Pica et al (1991) and which had been used as a fundamental resource for most recent studies of interaction and negotiation of meaning (Kasanga, 1996; Foster, 1998; Martyn, forthcoming; Roebers Forthcoming, Valera, 1999). Definitions and examples of negotiation of meaning exchanges as proposed by Pica et (1989) is summarized in the following figure.

Figure 2.2 Definition and examples of negotiation meaming exchange and its elements as adapted from Pica et al (1989)

1. NNS Trigger : Utterance followed by NS signal of total/partial lack of understanding

2. NS signal : of total or partial lack of understanding

a. Explicit Statement or Request for Clarification

e.g. NNS : I still don't know what the word is?

NS : the what?

b. Request for Confirmation through repetition of the NNS

e.g. NNS : on the right side

NS : on the right side?

c. Request for Confirmation through modification of the NNS

e.g. NNS : this is not uh this hasn't common nature NS : cars have common nature?

d. Request for Confirmation through completion or elaboration of NNS

e.g. NNS : sun and uh...

NS : rays 
3. NNS Response:

a. Switch to a new topic

b. Suppliance of information relevant to the topic, but not directly responsive to NS signal

c. Repetition of the NS modification of trigger

d. Self modification of trigger (Production of Modified language, i.e. "Comprehensible Ouput")

i. Phonological Modification

e.g. NNS : there is a zebra... you know ... zebras

NS : deborah?

NNS : zebra is what a $\mathrm{z}$...

ii. Semantic modification through synonym, paraphrase, or example

e.g. NNS : and this one have glass around the house...

NS : grass?

NNS : grass... plants, glass uh plants

iii. Morphological modification through addition, substitution, or deletion of inflectional morpheme (s) and/or functions

e.g. NNS : maybe we use we have use

NS : in the classroom you mean?

NNS : we have used already, huh

iv. Syntactic modification through embedding and elaboration in clause(s)

e.g. NNS : no a triangle, inside the triangle

NS : inside the triangle, there's another triangle?

NNS : above square, there's a triangle, and that sign in inside the triangle

e. Repetition of NNS trigger

f. Confirmation or acknowledgment of Signal only

g. Indication of difficulty or inability to respond

4. Response to NNS:

a. Comprehension Signal

b. Continuation move

(from Pica, Holliday, Lewis, and Morgenthaler, 1989)

\section{Negotiation of Meaning and Second Language Acquisition}

Pica (1996) suggests that although there has been no empirical evidence of the direct link between negotiation of meaning and second/ foreign language development, research studies in negotiation of meaning for the last two decades have shown that there are two obvious contributions of negotiation of meaning for second language acquisition. Firstly, through negotiation of meaning (particularly in interactions involving native speakers), non native speakers obtain comprehensible input necessary for second language acquisition much more frequent than interactions with negotiation of meaning. Secondly, negotiation of meaning provides opportunities for non-native speakers to produce comprehensible output necessary for second language acquisition much more frequent than in interactions with negotiation of meaning. Another important role of negotiation of meaning which may not have a direct impact to second language acquisition but is also an important element for second language learning through communication is that negotiation of meaning can function as an indication of communication pursue.

Comprehensible input in negotiation of meaning exchange is illustrated in the following two excerpts:

\section{Example 1:}

NS : it's got a chimney

NNS : chimney?

NS : that's where the smoke comes out of

(from Pica et al 1989)

Example 2:

NNS : How have increasing food costs changed your eating habits?

NS : Well, we don't eat as much beef we used to. We eat more chicken and uh, pork, and uh, fish, things like that.

NNS : pardon me?

NS : we don't eat as much beef as we used to. We eat more chicken and uh, uh pork and fish... we don't eat beef very often. We don't have steak like we used to.

(from Gass and Varonis, 1985).

Both examples 1 and 2 show the native speakers expressed utterances that were not understood by the non native speakers. In example 1 the non native speaker shows her non understanding by repeating the 
word 'chimney' The NS reacted to the confirmation check by trying to explain what the word 'chimney' means. In example 2 , the non native speaker shows non understanding by extending a request for clarification which was responded by the native speaker by repeating her previous utterance and adding some explanations. The two examples show how the native speakers justify their speech in order to help the non-native speakers to understand the message. It was believed that the non-native speakers' comprehension will help them acquire the target language form.

The second contribution of negotiation of meaning to language acquisition, that is, to provide opportunities for non native speaker to modify their output can be illustrated from the following two excerpts:

\section{Example 3:}

NNS : so there's a cross in the center of the paper

NS : what do you mean by cross?

NNS : traffic cross

NS : oh where people can cross? Or traffic light?

NNS : yes

(from Pica, 1992)

Example 4:

NNS : we have common patton in this case

NS : I don't know that word ... can you describe what it means

NNS : yes uh if I can explain the car's nature, we understand easy because car has a few-a lot of nature

(from Pica, 1988:88).

Both in examples 3 and 4, the native speakers expressed their non understanding for the message uttered by the non-native speakers by requesting for clarification of what have been said. In example 3 the nonnative speakers were 'forced' to change her utterance by adding the word 'traffic' for the intention. In example 4 the non-native speaker elaborated what he meant. The non-native speakers in examples 3 and 4 were forced to modify their output so that their utterances could be understood. Swain (1985) contends that second language learners acquire the target language if they are pushed to produce the target language. Moreover, Swain $(1985,1996)$ and Swain and Lapkins (1996) state that second language learners get three advantages of being pushed to modify their output. The first advantage is that learners get the opportunity to notice the gap between their current knowledge and the target language form. The second advantage is that learners get the opportunity to test their assumption about the target language form and the real target language form of the native speakers. The third advantage is that the second language learners get the opportunity to talk about the language (raise their metalinguistic awareness) through the interactions. As the examples have shown, the opportunity to gain comprehensible input and produce modifications of output is made available when the non-native speakers interact with the native speakers. Both modifications of input and modification of output contain a series of negotiation of meaning moves. The moves consist of a trigger (an utterance which cause communication breakdown), a trigger (an utterance of signalling misunderstanding by one of the interlocutor), a response to the trigger, and a follow-up move (Pica et al, 1989).

\section{Tasks and negotiation of meaning}

Until very recently, studies of negotiation of meaning and interactions can not be separated from tasks to elicit data. Data for negotiation of meaning can be obtained either from natural situation or from classroom setting. One example of study of negotiation of meaning in second language learning in natural setting is Gass and Varonis (1985). They assigned the subjects of the study to interview people through telephones. Although many interesting findings could be obtained from the study, the researchers found that this kind of data gathering technique is not easy to be applied.

Alternatively, almost all other studies of negotiation of meaning used tasks to elicit data.

Pica, Kanagy, and Falodun (1993) has proposed a typology of task based on the opportunity to interact and to negotiate meaning in interaction. This typology takes into consideration some interaction features in communicative activities such as interactant relationship, interaction requirement, goal orientation and outcome options.

Figure 3: Task relationship, requirement, goals and outcomes and their impact on opportunities for L2 learners' comprehension of input, feedback on production and modifications of interlanguage (after Pica, Kanagy and Falodun, 1993).

Based on the specification of interactant relationships and the interaction requirements which were then elaborated into the obligation to 
request or supply task-related information, and the goal orientation, Pica et al (1993) suggest that there are four conditions that should be met by a task in order to meet the communicative goal expected:

1. Each participant holds a different portion of information which must be exchanged and manipulated in order to reach the task outcome.

2. Both participants are required to request and supply this information to each other.

3. Participants have the same or convergent goals.

4. Only one acceptable outcome is possible from their attempts to meet this goal.

Courtney (1996), Futaba (1995), Martyn (forthcoming), Roebers (forthcoming) applied the task categorization in their studies. Courtney (1996) compared the quantity of negotiation of meaning of five tasks: an information gap tasks, a jigsaw task, a problem-solving task, a decision making task, and a role-play task. The tasks were given to ESL students in Hongkong. The result of his study shows that the tasks generated different number of negotiation of meaning. The study also found that the students in Hongkong rated Information gap tasks as the most encouraging tasks, followed by Jigsaw in the second position, Decision-making tasks in the third position, Problem-solving the fourth position and Role play in the fifth position.

\section{Dyadic Arrangements and Negotiation of Meaning}

Another important factor that will determine the amount of negotiation of meaning is the situation in which interaction takes place. Previous research of interaction and negotiation of meaning have shown that small group works generate more negotiation of meaning than teacher-fronted activities (Long and Porter, 1985). Foster (1998) found that dyadic activities stimulate second language learners to negotiate more than in small groups.

Plough and Gass (1993) conducted two embedded studies of interaction among NNS/NNS learners from the same and different L1 background. They try to find out the effect of familiarity with interlocutors and familiarity with tasks on the learners' performance. The first study involved ten NNS/NNS dyads of students in an intensive language program at a large American University. They categorized five of the dyads as familiar dyads because the participants had known each other at the time of the study was conducted while the other five dyads were considered unfamiliar dyads because they had not known each other. The dyads were assigned two communicative tasks, namely 'Spot the difference' and 'Who will survive'. Dependent variables comprise confirmation checks, echoes, back channel cues, clarification requests, overlaps and interruption, and sentence completion.

One of the results of the first study was that unfamiliar dyads used more conversation continuants than the familiar ones. Furthermore they summarized:

Assuming that indicators of non-understanding elicit greater negotiation work, which in turns facilitates the acquisition process, it would appear that familiarity between non-native speakers is yet another variables which may have an effect on how much participants are able to benefit from a conversation interaction. (p.46).

The second study of Plough and Gass (1993) was intended to see the effect of familiarity with the task on the patterns of interaction by NNSs. The study involves 18 dyads of NNS from the same and/or different L1 background. Nine of the dyads had been given the same kind of tasks prior to the experiment and the other nine dyads had been given the same kind of tasks. Two tasks were assigned to the participants, namely, 'Spot the difference and 'Who will survive'. The dependent variables were similar to the first study. They found that there was no significant difference in the performance of the familiar dyads and the unfamiliar dyads.

From the two studies, Plough and Gass (1993) came into three conclusions: firstly they saw that personal stylistic differences affect the participants' performance. Secondly, degree of familiarity with the interlocutor had a significant effect on the participants' performance. Thirdly, they found that task had a specific influence to the features of the interaction. They concluded that whoever the participants are, different task would result in different features of interaction.

\section{METHODOLOGY}

This study used a quasi experimental design: 'a design with a primary purpose of testing the existence of causal relationship among two or more variables and which the data were collected from two or more nonequivalent groups' (Hedrick at.al.1993:58-59). It is a quasi experiment in terms of the subject selection and the 'treatment' given to the subjects. The 
subjects of the study were not selected randomly but through a predetermined criteria of selection. The subjects were also given treatments through some predetermined conditions set for the study. However, the study was not a true-experimental design because it did not apply any control group for comparisons. Gal et al (1999) suggest that quasiexperiments are similar to true experiments, except that research participants are not randomly assigned to the treatment and control conditions (p.241).

\section{Subjects}

The subjects of the study were forty undergraduate students of English in the Faculty of Education at the University of Lampung studying English in order to be English teachers at junior and senior secondary schools upon the completion of their study. The subjects consisted of ten female students from the first grade, ten male students from the first grade, ten female students from the third grade and another ten male students from the third grade.

\section{Procedures}

Nine tasks consisting of three Information gap tasks, three Jigsaw tasks, and three Role-play tasks were given to be performed in dyadic interactions in three round activities. The first round activities included three tasks: the information gap (IG1), the jigsaw (JS1) and the role-play (RP1). The subjects of similar gender and similar proficiency were given these three tasks. In the second round, the subjects of different gender but similar proficiency level were paired. At this stage the subjects did three tasks: the role-play (RP2), the jigsaw (JS2) and the information gap (IG2). In the third round, the subjects of different gender and different proficiency levels were mixed.

These pairs implemented three different tasks: information gap (IG3), jigsaw (JS3), and role-play (RP3). The three information gap tasks were the kitchenette, general object maps and specific object maps. The three jigsaw tasks were spot the differences, the bear and the frog. The three role play tasks were the birthday invitation, returning defective toaster and job interview. (for complete description of tasks, see Yufrizal (forthcoming).

All conversations were transcribed using the convention of classroom interaction transcript of van Lier (1988) and coded based on the Pica et al (1989) scheme.Transcribed data then were exported to the NUDIST QSR computer program, a qualitative data analysis program (QSR NUD*IST, 1995) for further coding and analysis.

This program enabled us to do multiple index and coding, to obtain immediate access to the coding scheme and to do a crosschecking of the data obtained (see Patton, 1990:461).

\section{Data analysis}

In order to answer the research questions, two steps of analysis were conducted. The first research question is answered by analyzing the features of interactions using the coding scheme of Pica et al (1989) in order to see the patterns of negotiation of meaning, modifications of input and modifications of output.

The second and third research questions were answered statistically. A 3 × 3 design of Repeated Measures Analysis of Variance was conducted. The first three refers to three task types: Information gap tasks, Jigsaw tasks, and Role-play tasks. The second three refers to three dyadic arrangements: the same gender and the same proficiency dyads, different gender but the same proficiency dyads, and different gender and different proficiency dyads. The repeated measures are conducted on four dependent variables: the number of c-units representing the quantity of interaction, the negotiation of meaning sequences, the modifications of input, and the modifications output.

\section{RESULTS AND DISCUSSION}

\section{The Negotiation of Meaning by Indonesian EFL Learners}

The negotiation of meaning activities of Indonesian EFL learners can be seen from the following examples:

\section{Example 5}

1. LINA : and his hair...

2. UCI : his hair?

3. LINA : is separately.

4. UCI : separately?

5. LINA : separately.

6. UCI : what do you mean separately?

7. LINA : not lay down...nggak lurus 
8. UCI : oh it's not straight down .

9. LINA : it's divided into two

10. UCI : oh, I see.

Example 5 shows an extension of conversation among the two interactants due to misunderstanding or potential of misunderstanding on one item, that is, the hair style discussed in the task. Furthermore, the example also shows the intensity of involvement of the two speakers by giving signals and responses for an unclear item. This might be different from a series of exchanges that do not involve negotiation of meaning sequences as shown in Example 6 below.

\section{Example 6}

1. ADI : the hair is uh, ..., middle cut may be (Trigger)

2. COKI : middle cut so? (Confirmation check repetition)

3. ADI : balance between the $u h, .$. , right side and the left side

4. COKI : the right side..., o you mean ..., ...,

5. so ..., ..., ..., it's ..., ..., wrong

6. mine... mine is not middle cut (Side sequence)

7. ADI : oh no your your in your picture is not middle cut

8. COKI : yeah ..., ..., ..., side cut (self expansion response)

9. and what about the glasses (Follow-up)

10. ADI : glasses is a square

11. COKI: square ..., so it's not ..., not like a cycle..., cycle glasses 12. oh, ..., ...., I see

13. and uh, ..., ..., what else what about the nose ..., nose

14. ADI : the nose uh ...,...,..., ..., ..., the nose is uh ....,

15. I think is normally nose

16. but I this is $u h, \ldots, \ldots$, are $u h, \ldots, \ldots, \ldots$ uh hmm ..., line not line

17.

but may be ..., ..., ..., horizontal may be ..., but not not horizontal

18.

yes I think is ..., is /normally nose/

19. COKI : /normally nose/ ..., ..., ..., ..., uh hmm ..., ...,

20.

what about the eyes

21. ADI : the eyes is like Chinese

Example 6 shows an exchange was between two male lower proficiency learners. The exchange in Example 6 contains 11 turns taken, in which Coki produced five turns and ADI produced six turns. In terms of c-units, the exchanges contained 21 c-units, in which Coki produced eleven cunits, while ADI produced ten c-units. The example also shows a combination of negotiated exchanges and non-negotiated exchanges. The negotiation exchanges began when ADI extended an utterance that functions as a trigger (line 1). This caused the listener COKI to extend a signal for negotiation of meaning (line 2). Lines 4-6 show the utterances which functions as the 'reaction to response' (Gass and Varonis, 1985) but they also contain a new trigger which also function as a side sequence (Pica et al, 1989, 1991). The negotiation exchange ended when COKI extended a self expansion response in line 8 and changed the topic of the conversation in line 9 . Line 10 has a potential for a negotiation of meaning, but the listener (lines 11-13) did not extend a signal for negotiation of meaning and just continued the conversation. Line 14-21 shows a flow of conversation that did not involve negotiation of meaning sequences. Example 6 shows that lines 1-8 contained an exchange of conversation involving only one topic of conversation, while lines 9-21 shows an exchange of conversation involving four different topic of conversations. A more extended conversation was made in interaction containing negotiation of meaning than in conversation which does not contain negotiation of meaning.

The two examples above showed that a longer conversation occurs when the interlocutors involved in negotiation of meaning than without negotiation of meaning. An exchange with negotiation of meaning usually involves both participants to ask and answer intensively while non negotiated exchange may involve longer conversation but with one of the participant tends to dominate as shown in lines 14-18 of Example 6 above. The more the participants involved in negotiation of meaning the more likely that they are willing to pursue and maintain the conversations. Kasanga (1996) mentions that such function of negotiation of meaning as an indication of conversation pursuant.

\section{Negotiation of Meaning and Modification of Input}

Modifications of input in a conversation among non-native speakers are realised in confirmation check through completion or correction and confirmation check through elaboration and modifications (see Pica et al, 1989). Another kind of confirmation check, that is, through repetition is not included as an indication of modification of input. 
The following three examples show the three kinds of confirmation checks.

\section{Example 7:}

Rara : uh... this is the hotel Royal

Panjul : hotel Royal?

Rara : yeah

Panjul : ok

In example 7 the speaker produced an utterance which triggerred the listener to extend a signal for negotiation of meaning by repeating part of the speakers' utterance. This signal is a confirmation check where the listener wanted to ensure whether he heard the correct thing. The confirmation check resulted in a response in the form of confirmation from the speaker. This exchange did not result in modification of input from the listener nor modification of output by the speaker.

Example 8:

Gareng : the mouth is like uh the people uh, ... when when the people hungry maybe

Weli : angry you mean?

Gareng : angry oh... I'm sorry angry

Example 8 shows a confirmation check by giving correction by the listener. This resulted in a modification of output by the speaker.

Example 9:

CENIL : uh I think he has uh small eyes

COKI : small eyes

I mean you mean that she is like a Chinese I mean?

CENIL : yes, yes

COKI : OK

Example 9 shows that the trigger produced by the speaker (CENIL) resulted in the listeners' signal for negotiation of meaning by extending a confirmation check. However, the listener did not only repeat what she heard but also elaborating his understanding.

This results in a response in the form of confirmation by the speaker. The exchange resulted in a modification of input by the listener but not modification of output by the speaker.

\section{Negotiation of Meaning and Modifications of Output}

The followings are examples of modifications of output in negotiation of meaning exchanges among Indonesian EFL learners.

\section{Example 10}

Noni : /he/ saw he saw

Pujo : she saw a frog

Noni : she saw I'm sorry she saw

(Noni is female lower com Pujo is higher male com)

In example 10, the listener (Pujo) provides a corrective feedback or recast (Mackay and Philp, 1998; Mackay, 1999) to the speaker's utterance. Pujo's corrective feedback contained a cue (Holliday, 1995) that made the speaker modified her output by repeating the correction. In this exchange the speaker 'noticed' her mistake of the pronoun 'he' instead of 'she'.

\section{Example 11:}

Panjul : he see a frog she see a frog the frog is on the water $., \ldots, \ldots$, yeah, it seems it's on uh... what is it kind of leafs on the waterand then he (just) she just smile the girl is stand on the left side of the picture

Noen : do you mean that she's watching the frog

Panjul : yeah she's watching the frog

Noen : yeah

In example 11 the listener (Noen) tried to confirm the long explanation from the speaker (Panjul) by simplifying it into a simpler sentence. The speaker modified her long utterances by repeating the signal. Thus, example 11shows an exchange where the listener provides corrective feedback and the speaker responded by correcting his utterance following the 'targetlike' form provided by the listener. In this exchange the speaker had not only noticed his ungrammatical sentence but also raised his metalinguistic function (Swain, 1996). It was through the two functions of modification of output the learners (Noni in Example 10 and Panjul in Example 11) improve their English proficiency.

\section{Example 12:}

Adi : may be you was done

Coki : pardon? 
Adi : was ..., was done you test on ..., on the last week Coki : yea ...,..., by the way

The clarification request extended by the listener (Coki) was responded by the speaker (Adi) by trying to elaborate his previous utterance. Even though the elaboration made by Adi was still in non target like form. The listener did not extend any further correction of this 'ill-formed utterance. The reaction of the listener was just move to the other topic or ignore the error. This could be understood by the fact that both interlocutors have limited mastery of the target language. However, Adi (the speaker) has made an attempt to modify his output.

Example 13:

Gareng : uh how about the what is it the button in his coat there their what how many how many button in your picture in your picture I think

Petruk : pardon me

Gareng : in his in his coat in your picture the man use coat right

Petruk : oh coat use a coat yes I see

Example 13 showed a conversation among leamers with higher mastery of the second language. The clarification request extended by the listener (Gareng) was responded by the speaker by modifying his output in a more target like utterance. The result as can be seen from the reaction by the listener was a more comprehension of the message being heard.

\section{Example 14:}

Nani : wh... the frog .,...........,

Lina : keep away?

Nani : the frog keep away from from the bottle

Lina : ok, and he

(Nani is female lower conc, Lina is female higher conc)

Example 14 shows that the speaker (Nani) was not certain of the expression she needed to use. The listener Lina provided the phrase 'keep away' which was then used by Nani to elaborate her ideas. Thus Nani had modified her output by using the cue provided by Lina.

\section{The Effects of Task Type and Dyadic Arrangements on the} Interactions

The following two tables summarized the descriptive statistics of the subjects' performance on four dependent variables: the number of c-units, the number of negotiation of meaning sequences, the number of modifications of input and the number of modifications of output.

Table 1 summarized the descriptive statistics according to the three task types and Table 3 summarizes the descriptive statistics according to the three dyadic arrangements.

Table 1 Summary of descriptive statistics of the distribution of dependent variables in the three task types

Table 2: Summary of descriptive statistics of the distribution of dependent variables in the three dyadic arrangements

Table 4: Summary of repeated measures ANOVA on tasks and dyadic arrangements Independent dependent

\begin{tabular}{lccc}
\hline T Probability & df & sig & Task \\
\hline C-unit & 57.268 & 2 & .000 \\
Neg.mean sequence & 91.943 & 2 & .000 \\
comp.input & 13.803 & 2 & .000 \\
comp.output & 31.408 & 2 & .000 \\
& & & \\
Dyad & & & .061 \\
C-unit & 3.010 & 2 & .287 \\
Neg.mean sequence & 1.292 & 2 & .503 \\
comp.input & .700 & 2 & .292 \\
comp.output & 1.273 & 2 & \\
& & & .000 \\
Task x Dyad & & & .002 \\
C-unit & 17.997 & 4 & .066 \\
Neg.mean sequence & 5.123 & 4 & \\
comp.input & 2.419 & 4 & \\
comp.output & 2.392 & 4 & \\
\end{tabular}

Table 4 showed task types had significant influences on the four dependent variables. This means that Information gap tasks, Jigsaw tasks, and 
Role-play tasks generated different c-units, negotiation of meaning sequences, modifications of input and modifications of output. The table also shows that dyadic arrangements did not have significant effect on the number of c-units, negotiation of meaning sequences, modifications of input, and modifications of output. The repeated measures ANOVA reveals that there was a two-way interaction effect between task type and dyadic arrangements on the number of c-units and negotiation of meaning sequences. There was significant interaction of task types and dyadic arrangements on the comprehensible input and comprehensible output. The effect of task type and dyadic arrangements is illustrated in the following figures.

Figure 3: The interaction effect between dyadic arrangement and task types on c-units

The left-hand graph of Figure 3 shows the distribution of the number of c-units across the three task types and three dyadic arrangements. As the figure reveals, there was a variation of the amount of interaction by the three task types in the three dyadic arrangements. The greatest interactions were generated by the same gender and the same proficiency dyads in Information gap tasks. The greatest interactions were generated by different gender but the same proficiency dyads in Jigsaw tasks, and most interaction was generated by different gender and different proficiency in Role-play tasks. However, in terms of negotiation of meaning sequences, as the right-hand figure shows, learners produced the most negotiation of meaning sequences when they are paired into the same gender and the same proficiency dyads in Information gap tasks and Jigsaw tasks. Learners produced the least negotiation of meaning sequences in Information gap tasks and Jigsaw tasks when they were applied the task Different Gender and Different Proficiency Dyads. However they produced the most negotiation of meaning when they applied Role-play tasks.

This also strengthens the previous analysis on the effect of dyadic arrangements on the interaction. Learners felt more comfortable talking with closer peers in 'convergent tasks' than in 'divergent tasks'. Therefore, they made more effort to modify input, correcting errors and modify outputs in the convergent tasks more loosely to their close peers than to less-known peer.
The fact that students made more negotiation of meaning in Role-play tasks when they were assigned Different Gender and Different Proficiency Dyads is a different interesting fact. As had been mentioned previously, in Dyad 3 the subjects were paired with less familiar peers. With this dyadic arrangement, students did not feel comfortable of making modification of input as well as correcting others'. The graphs showed that the least negotiation of meaning sequences were produced in this kind of dyad applying both Information Gap tasks and Jigsaw tasks. Students produced more negotiation of meaning sequences in Role-play tasks might be due to the presence of 'more senior students' speaking to the 'more junior students'. The higher proficiency students here function as the more proficient speakers. This might be parallel to the function of native speaker in the NS-NNS interaction. As a summary, Indonesian EFL students produced more interaction and more negotiation of meaning when they are paired with closer peers applying convergent tasks such as Information Gap tasks and Jigsaw tasks. The students will produce more interaction and negotiation of meaning when they are paired with less familiar partners applying more divergent tasks such as role-play, information exchange and so on.

Figure 4: The interactional effect between task type and dyadic arrangement on modifications of output

The figure reveals that more modifications of output were produced by learners in the same gender and the same proficiency dyads for the three task types than in the other two dyads. Learners produced the least modifications of output in different gender and different proficiency dyads. This result seems to confirm Varonis and Gass (1985) "We further suggest that negotiation work is greater in NNS-NNS discourse than in any other types of discourse and that, hence, it is a good forum for obtaining input necessary for acquisition" (p.83).

\section{CONCLUSTON}

Four conclusions that can be drawn from the analysis are:

1. In terms of task types, Information gap tasks played a leading role compared to the other two tasks. Information gap tasks were proven to generate the longest time of speaking, the number of turns taken, and the number of c-units (the greatest amount of interaction). 
Information gap tasks were also proven to be dominant in producing the number of negotiation of meaning sequences, the number of signals for negotiation, of meaning, the number of responses for negotiation of meaning, and the number of modifications of output. In the number of modifications of input, Information gap tasks produced as many modifications of input as the Jigsaw tasks.

Similarly, Jigsaw tasks produced more quantity of interactions and negotiation of meaning than Role-play tasks. Information gap tasks were also better than the other two task types in generating the components of signals for negotiation of meaning (confirmation checks and clarification requests) and the components of responses for negotiation of meaning (self-repetition, other-repetition, self-expansion, other-expansion, and confirmation and negation responses. This results support previous studies of negotiation of meaning such as Pica et al, 1989; 1991; Courtney, 1996; Martyn, forthcoming where Information gap tasks were found the produce more negotiation of meaning than jigsaw tasks. This study contradicts Futaba's (1995) study who found that Jigsaw tasks produce more negotiation of meaning than Information gap tasks. Although, Futaba (1995) admits that the difference was due to the content of the tasks rather than to the difference between the two task types.

2. In terms of dyadic arrangements, Indonesian EFL learners were found to produce more interaction and negotiation of meaning in The Same Gender and The Same Proficiency Dyads when they were assigned Information gap tasks and Jigsaw tasks. However, Indonesian EFL learners were found to produce more interaction and negotiation of meaning in Different Gender and Different Proficiency Dyads applying divergent tasks such as role-play task.

3. Other finding from the study which was not analysed statistically but which logically influence the amount of interaction was the contents of the tasks and familiarity among interlocutors and familiarity between the interlocutors and the types of task.

Comparisons of the contents among one task to another discussed previously showed that the three Information gap tasks contain more items that might cause misunderstanding than the three Jigsaw tasks and the three Role Play tasks, and the contents of the three Jigsaw tasks contain more items that might cause misunderstanding than in the three Role-play tasks. Additionally, comparison between each task also shows variation of content difficulty. In information gap tasks, relatively the same number of items that might have caused communication misunderstanding could be identified. In Jigsaw tasks, 'spot the difference task' (Jigsaw 1) contains more items that caused misunderstanding than Jigsaw 2 and Jigsaw 3. Role-play tasks require improvisation by the participants. However, 'Job interview task' (Role-play 3) might create more difficulty than the other two tasks, while 'Returning defective toaster' (Role-play 2) might create more difficulty than 'Birthday invitation task' (Role-play 1).

The most important finding was in the negotiation of meaning sequences and modifications of output. The negotiation of meaning sequences show one of the function of negotiation of meaning as an indicator of conversation pursuant or abandonment (Kasanga, 1996 b). The more negotiation of meaning sequences were made, the more likely that the participants more involved in the conversations. The modifications of output reflect the most important function of negotiation of meaning, that is, language acquisition. Through the modifications of output, the subjects modify their performance and thus improved their language acquisition (Swain, 1985; Swain and Lapkins, 1995). The current study shows that in terms of task type it was through information gap tasks the subjects produced more negotiation of meaning sequences and thus involved in the prolonged conversation. However, the maximum negotiation of meaning was produced in the same gender and the same proficiency dyads in Information gap tasks and Jigsaw tasks. The greatest numbers of negotiation of meaning were produced by different gender and different proficiency dyads in Role-play tasks. The most important finding was that the Indonesian EFL learners can gain language acquisition by modifying their output when they are paired in the same gender and the same proficiency dyads rather than in different gender but the same proficiency dyads or in different gender and different proficiency dyads.

Some questions remained unanswered in this study. For example, the benefit of learners who get the opportunity to modify their output was evident, that is, to help them acquire the language through the output. Analyses and examples from previous chapters showed that learners also provide modifications of input which has a clear function to help the interlocutor to comprehend the message. Previous research has discussed the role of modification of input in relation to the native speaker helping 
the non native speaker to comprehend message but there has no further analysis of whether the EFL learners who tend to provide modifications of input will also improve their second language development.

Research has proved that communication interactions could help accelerate learners' second/foreign language development. Therefore it is suggested that teachers provide more opportunities for learners to interact each other both in and outside classroom.

The study has also shown that the absence of native speaker could be manipulated by combining students from lower proficiency and higher proficiency levels in the conversations. Therefore, combining students from lower and higher proficiency levels help the lower proficiency students gain from their more senior peers while the higher proficiency learners get the opportunity to apply their second language knowledge, providing corrective feedback and noticing on form from the interaction with their lower proficiency peers.

\section{CONCLUDING REMARKS}

Although the study could not perfectly illustrate how EFL learners get benefits from interacting with each other in the target language, the study has been able to show how EFL learners in Indonesia negotiate meaning and acquire the target language from the interaction. The results of the study are expected to extend the horizons for the second language acquisition field of research which had mainly focused on the interactions which involve native speakers, or at least involving the researcher as the native speaker. There are still many aspects of EFL teaching and learning phenomena that seemed to be neglected in the studies of second language acquisition. As a result, many non-native speaker-EFL teachers should adopt materials developed based on research studies by native speaker researchers. Sometimes the materials suit to the social and cultural situations of the students and sometimes not. Therefore, published research studies on EFL learning situations by EFL researchers need to be supported so that balanced information and learning resources can be achieved and thus help learners develop their second language knowledge proportionately.

\section{REFERENCES}

Alcon, Eva. 1998. Input and Input Processing in Second Language Acquisition. IRAL 36 (4), 343-361.

Courtney, M. 1996. Talking to Learn: Selecting and Using Peer Group Oral Task. English Language Teaching 50 (4).

Crookes, G. 1991. Second Language Speech Production Research. Studies in Second Language Acquisition, 13, 113-132.

Crookes, G and Gass, S (Eds.). 1993. Tasks in a Pedagogical Context: Integrating Theory and Practice. Clevedon: Multilingual Matters, Ltd.

Doughty, C., and Pica, T. 1986. Information Gap Tasks: Do they facilitate second language acquisition?. TESOL Quarterly, 20 (2).

Duff, P.A. 1986. Another Look at Interlanguage Talk: Taking Task to Task. In R.R. Day (Ed.)

Ellis, R., Tanaka, Y and Yanakazi, A. 1994. Classroom interaction, comprehension and L2 vocabulary acquisition. Language Learning. 551, 1-32.

Foster, P. 1998. A Classroom Perspective on the Negotiation of Meaning. Applied Linguistics 19 (1), 1-23.

Foster, P. and Skehan, P. 1996. The Influence of Planning and Task Type on Second Language Performance. Studies on Second Language Acquisition, $18,299-323$.

Futaba, T. 1994. Second Language Acquisition through Negotiation: A Case on Non-Native Speakers who Share the Same First Language. Unpublished Ph.D. Dissertation. The University of Pennsylvania.

Gal, J.P., Gal, M.D., and Borg, W.R. 1999. Applying Educational Research: A practical guide. New York: Longman.

Gardner, R.C. 1985. Social Psychology and Second Language Learning: The Role of Attitudes and Motivation. London: Edward Arnold.

Gass, S.M. 1997. Input, Interaction, and Second Language Learner. Mahwah, New Jersey: Lawrence Erlbaum Associate, Inc., Publishers.

Gass, S.M. 2000. Fundamentals of Second Language Acquisition. In J.W. Rosenthal (Ed.), Handbook of Undergraduate Second Language Education (pp.29-46). Mahwah, New Jersey: Lawrence Erlbaum Associate, Inc., Publishers.

Gass, S.M., and Varonis, E.M. 1985. Task Variation and Non-native/Non-native Negotiation of Meaning. In S.M. Gass and C.G. Madden (Eds.), Input in Second Language Acquisition (pp.149-161). Cambridge, MA: Newbury House.

Gass, S.M. and Varonis, E.M. 1986. Sex Differences in Non-native Speaker-nonnative Speaker Interactions. In R.R. Day (Ed.). Talking to Learn: Conversation in Second Language Acquisition. (pp.327-351. Rowley, MA: Newbury House.

Gass, S.M. and Varonis, E.M. 1994. Input, interaction and second language production. SSLA, 16(3): 283-302. 
Girden, E.R. 1992. ANOVA Repeated Measures. Newbury Park: Sage Publications.

Hedrick, T.E., Bickman, L., and Rog, D.J. 1993. Applied Research Design: A Practical Guide. Thousand Oaks London: Sage Publications.

Holliday, Lloyd. 1995. NS Syntactic Modifications in NS-NNS Negotiation as Input Data for Second Language Acquisition of Syntax. Unpublished Ph.D. Dissertation. University of Pennsylvania.

Jauregi-Ondarra, K. (forthcoming) Collaborating in the Process of Negotiation of Meaning: a Longitudinal Approach.

Kasanga, L.A. 1996a. Effect of gender and therRate of interaction: Some implications for second language acquisition and classroom practice. ITL. Review of Applied Linguistics, 111-112, 155-192.

Kasanga, L.A. 1996b. Peer Interaction and L2 Learning. The Canadian Modern Language Review 52 (4), 611-639.

Krashen, S. 1980. The Input Hypothesis. In J.E. Alatis (Ed.), Current Issues in Bilingual Education (pp.168-180). Washington, D.C.: Georgetown University Press.

Krashen, S. 1981. Second Language Acquisition and Second Language Learning. Oxford. Pergamon Press.

Krashen. S 1982. Principles and Practice in Second Language Acquisition. Oxford: Pergamon Press.

Krashen, S. 1985. The Input Hypothesis: Issues and Implementations. London: Longman.

Linnel, $\mathrm{J}$ (forthcoming). Linguistic Modifications in Negotiations of Meaning: A Study with Finnish as a Target Language.

Long, M.H. 1981. Input, Interaction and Second Language Acquisition. In H. Winitz (Ed.), Native Language and Foreign Language Acquisition. Annals of the New York: Academy of Science 379:259-278.

Long, M.H. 1981. Questions in Foreigner Talk Discourse. Language Learning, 31 (1).

Long, M.H. 1983. Native Speaker/Non-native Speaker Conversation in the Second Language Classroom. In M Clarke and J. Handscombe (Eds.), Pacific Perspectives on Language Learning and Teaching. Washington D.C.:TESOL.

Long, M.H. 1983. Linguistic and Conversational Adjustments to Non-native Speakers. Studies in Second Language Acquisition, 5, 177-193.

Long, M.H. 1983. Native Speaker/Non-native Speaker Conversation and the Negotiation of Comprehensible Input. Applied Linguistics, 4 (2), 126-141.

Long, M.H. 1985. A Role for Instruction in Second Language Acquisition: Task Based Language Training. In K. Hyltenstam and M Pienemann (Eds.), Modelling and Assessing Second Language Acquisition. London: Multilingula Matters.
Long, M.H. 1985. Input and Second Language Acquisition Theory. In S.M. Gass and C.G. Madden (Eds.), Input in Second Language Acquisition (pp.377393). Cambridge, MA.: Newbury House.

Long, M.H. 1990. Task, group, and task-group interactions. In S. Anivan (Ed.), Language Teaching Methodology for the Nineties (pp.31-50). Singapore: Seameo RELC.

Long, M. 1996. The Role of the Linguistic Environment in Second Language Acquisition. In W.C. Ritchie and T.K. Bhatia (Eds.), Handbook of Second Language Acquisition (pp.413-486). New York: Academic Press.

Lyster, R. 1998. Recasts, repetition, and ambiguity in L2 classroom discourse. Studies in Second Language Acquisition, 20, 51-81.

Lyster, R., and Ranta, L. 1997. Corrective feedback and learner uptake: Negotiation of form in communicative classrooms. Studies in Second Language Acquisition, 19, 37-66.

Mackey, A. 1995. Stepping Up the Pace: Input, Interaction and interlanguage development: An empirical study of questions in ESL. Unpublished doctoral dissertation, University of Sydney, Australia.

Mackey, A and Philp, J. 1998. Conversational interaction and second language development: Recasts, responses, and red herrings? The Modern Language Journal, 82 (3):338-356.

Martyn, $\mathbb{E}$. (forthcoming). The effect of task type on negotiation of meaning: $A$ quantitative Appraisal.

Nabuyoshi, J. and Ellis, R. 1993. Focused communication tasks and second language acquisition. English Language Teaching Journal, 47, 203-210.

Nunan, D. 1989. Designing Tasks for the Cmmunication Cassroom, Cambridge: Cambridge University Press.

Nunan, D. 1993. Task-Based Syllabus Design: Selecting, Grading, and Sequencing Tasks. In Gass and Crookes (eds.) Task in a pedagogical context: Integrating theory and practice. Clevedon, Multilingual Matters, Ltd.

Oliver, R. 1998. Negotiation of meaning in child interactions. Modern Language Journal, 82, 372-386.

Oliver, R. 2000. Age differences in negotiation and feedback in classroom and pairwork. Language Learning 50, 119-151.

Patton, M. Q. 1990. Qualitative Evaluation and Research Methods. Newbury Park: Sage.

Pica, T. 1987a. Interlanguage adjustments as an outcome of NS-NNS negotiated interaction. Language Learning, 38 (1), 45-73.

Pica, T. 1988. Second language acquisition, social interaction, and the classroom. Applied linguistics, 8 (1) 3-21.

Pica, T. 1991a. Classroom interaction, negotiation, and comprehension: Redefining Relationship. System, 19 (4), 437-452. 
Pica, T. 1994a. Research on negotiation: What does it reveal about second language learning conditions, processes, and outcomes? Language Learning 44 (3) 493-527.

Pica, T \& Doughty, C. 1985. The Role of Group Work in Classroom Second Language Acquisition. Studies in Second Language Acquisition, 7, 233-248.

Pica, T. \& Doughty, C. 1988. Variations in Classroom Interactions as a Function of Participation Pattern and Task. In J. Fine (Ed.), Second Language Discourse: A Textbook of Current Research (pp.41-55). New York: Ablex.

Pica, T.,\& Young, R. 1986. Making input comprehensible: Do interactional modifications help? I.T.L. Review of Applied Linguistics, 72, 1-25.

Pica, T.,Holliday, L., Lewis, N., Berducci, D., \& Newman, J. 1991. Language learning through interaction: What role does gender play? Studies in Second Language Acquisition, 13.(2), 343-376.

Pica, T. Holliday, L., Lewis, N., \& Morgenthaler, L. 1989. Comprehensible output as an outcome of linguistic demands on the learner. Studies in Second Language acquisition, 11, 63-90.

Pica, T., Kanagy, R., \& Falodun, J. 1993. Choosing and using communication tasks for second language instruction and research. In G. Crookes \& S. Gass (Eds.). Tasks and Second Language Learning (pp.1-22). Cleveland: Multilingual Matters.

Pica, T., Young, R., \& Doughty, C. 1987. The impact of interaction on comprehension. TESOL Quarterly, 21 (4), 737-758.

Pica, T., Lincoln-Parker, F., Paninos, D., And Linnel, J. 1996. Language learner's interaction: How does it address the input, output, and feedback needs of L2 learner? TESOL Quarterly, 30, 59-84.

OSR NUD*IST (Application Software Package, Version 4). 1995. Melbourne: Qualitative Solutions and Research.

Rietveld, T. and van Hout, R. 1993. Statistical Techniques for the Study of Language and Language Behavior. New York: Mouton de Gruyter.

Roebers, J. (forthcoming). Keep on Talking: Comprehensible Output as a Result of Negotiation of Meaning among EFL Learners within Different Task Types.

Shehadeh, A. 1999. Non-native Speakers' Production of Modified Comprehensible Output and Second Language Learning. Language Learning. 49(4): 627-675.

Skehan, P. 1998. A Cognitive Approach to Language Learning. Oxford: Oxford University Press.

Swain, M. 1985. Communicative Competence: Some roles of Comprehensible Input and Comprehensible Output in its development. In S.M. Gass and C.G. Madden (Eds.), Input in Second Language Acquisition (pp.235-253). Cambridge, MA.: Newbury House.

Swain, M. 1993. The Output Hypothesis: Just Speaking and Writing aren't Enough. The Canadian Modern Language Review, 50, 158-164.
Swain, M. 1995. Three functions of output in second language acquisition. In G. Cook and B. Seidlhofer (Eds.), Principle and Practice in Applied Linguistics (pp.125-144). Oxford: Oxford University Press.

Swain, M. 1995. Three functions of output in second language acquisition. In G. Cook and B. Seidlhofer (Eds.), Principle and Practice in Applied Linguistics (pp.125-144). Oxford: Oxford University Press.

Van den Branden. K. 1997. Effects of negotiation of language learner's output. Language Learning. 47, 589-636.

Varonis, E.M. \& Gass, S.M. 1982. The Comprehensibility of non-native speech. Studies in second language acquisition, 4, 114-136.

Varonis, E.M. \& Gass, S.M. 1985a. Miscommunication in native/non-native conversation. Language in Society, 14, 327-343.

Varonis, E.M. \& Gass, S.M. 1985b. Non-native/Non-native conversations: A model for negotiation of meaning. Applied Linguistics, 6 (1), 71-90. 